\title{
Isolated atresia of the aortic arch in a 65-year-old man Surgical treatment and review of published reports
}

\author{
SIMCHA MILO, CARLO MASSINI, „ DANIEL A GOOR \\ From the Department of Thoracic and Cardiovascular Surgery and the Sheba Heart Institute, The Chaim Sheba \\ Medical Center, Tel-Hashomer, Israel
}

SUMMARY A 65-year-old patient with isolated aortic arch atresia documented by cardiac catheterisation and cineangiography is described. Successful surgical repair was performed using a $10 \mathrm{~mm}$ Dacron tube graft to bypass the atretic segment.

Isolated atresia of the aortic arch is rare. In aortic arch atresia the arch is continuous, yet a segment of it is atretic so that apart from a collateral circulation, communication with the lower aortic segment is absent. Haemodynamically, the condition is similar to complete interruption of the aortic arch.

To our knowledge only 10 cases of isolated aortic arch atresia or interruption have been reported..$^{1-9}$ In eight cases, the diagnosis was confirmed at operation, one case was diagnosed but untreated, ${ }^{8}$ and in one patient, the diagnosis was made at necropsy. ${ }^{1}$

In this report we present a 65 -year-old man with isolated atresia of the aortic arch which was subsequently corrected by operation. The anatomical aspects, diagnostic problems, and surgical approach are discussed, with a review of the previously published cases.

\section{Case history}

A 65-year-old Bedouin man was referred to the Sheba Medical Centre for evaluation of shortness of breath, dizziness, palpitation, fatigue, and cachexia of one year's duration. On admission he was in poor general condition, cachectic, and dyspnoeic at rest. The blood pressure in the right arm was $145 / 120 \mathrm{mmHg}$ but it could not be measured in the left arm. There was no cyanosis. Examination of the neck showed distinct enlargement of the neck veins. The right carotid artery was normal; the left carotid was palpable but very weak. The chest was symmetrical and aeration of

*A visiting fellow from the Department of Cardiovascular Surgery, Ospedale Specializzato Regionale "G.M. Lancisi", Ancona, Italy. the lungs was equal. The apex of the heart was visible and palpable in the sixth intercostal space in the anterior axillary line. Examination of the back disclosed arterial pulsation in the intercostal spaces on the right side only. The liver was enlarged $3 \mathrm{~cm}$ below the right costal margin and was tender to palpation. The femoral and peripheral leg pulses were not palpable bilaterally. The electrocardiogram showed sinus rhythm, enlargement of both atria, left ventricular hypertrophy, and strain. Chest $x$-ray film showed right sided rib notching. The haemoglobin was 14.7 $\mathrm{mg} / 100 \mathrm{ml}$; WBC 7900 ; blood urea $7.0 \mathrm{mmol} / \mathrm{l}(42$ $\mathrm{mg} / 100 \mathrm{ml})$; serum creatinine $79.6 \mathrm{mmol} / \mathrm{l}(0.9 \mathrm{mg} /$ $100 \mathrm{ml}$ ). Cardiac catheterisation was performed via a percutaneous Seldinger right axillary approach. Thoracic aortography showed interruption of the aortic arch before the origin of the left subclavian artery (Fig. 1A and B), with late filling of the descending thoracic aorta via a collateral circulation, especially the left vertebral artery (Fig. 2A and B).

At operation a left thoracotomy was made in the fourth left intercostal space. The aorta was dissected $\widetilde{N}$ retrogradely, freeing the left subclavian artery which was small, approximately $3 \mathrm{~mm}$ in diameter. Further dissection of the aortic arch disclosed a narrow, $3 \mathrm{~mm}$ long segment of the aorta between the left subclavian artery and the left common carotid artery; no lumen was present. The left common carotid and right $\mathbb{D}$ brachiocephalic trunk were dissected. A $10 \mathrm{~mm}$ woven Dacron graft was anastomosed to the left side of the brachiocephalic trunk using partial occlusion $\stackrel{0}{\mathbb{D}}$ and was connected to the distal descending thoracic $\frac{?}{\mathbb{D}}$ aorta using the same technique (Fig. 3). After comple- $\stackrel{\mathbb{Q}}{2}$ tion of the anastomoses, a mean blood pressure of 80 웅 

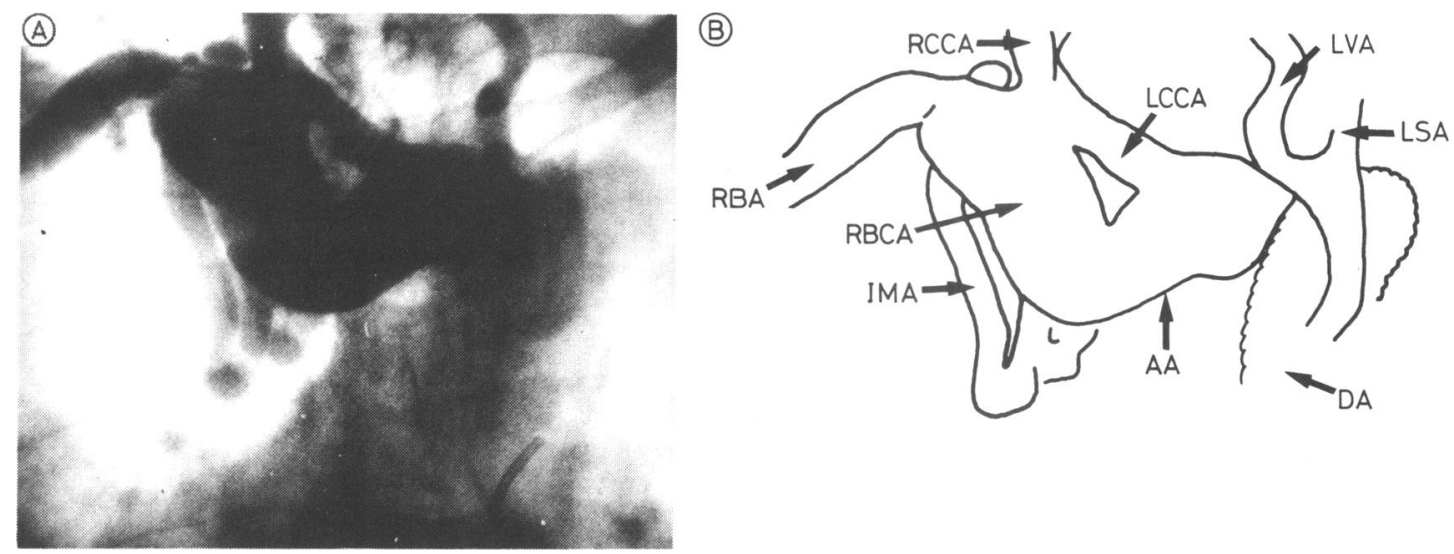

Fig. 1 (A) The early phase of the ascending thoracic arteriogram in the right anterior oblique position. The brachiocephalic trunk is conspicuously dilated. Contrast material does not enter the descending thoracic aorta. (B) Diagrammatic representation of Fig. $1 A$ Contrast material introduced into the ascending aorta $(A A)$ through the right brachial artery $(R B A)$ flows into the right brachiocephalic artery (RBCA) and right common carotid artery (RCCA), left common carotid artery (LCCA), and the internal mammary artery (IMA). The descending aorta $(D A)$ is supplied later through the vertebrobasilar system. Blood flows via the left vertebral artery (LVA) into the left subclavian artery (LSA) and into the descending aorta.
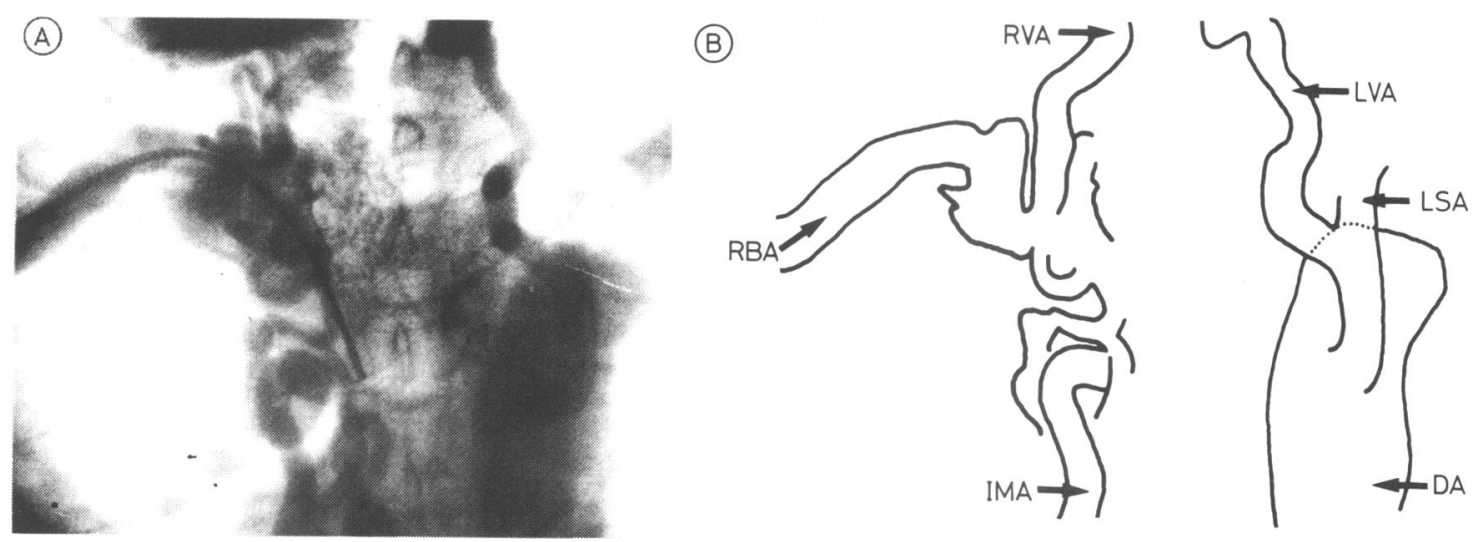

Fig. 2 (A) A late phase picture of the thoracic arteriogram in the right anterior oblique position. The internal mammary artery is much enlarged and tortuous. The descending thoracic aorta is now visualised. The right and left vertebral arteries are seen with dense opacification of the left vertebral artery. (B) Diagrammatic representation of Fig. $2 A$. $R B A$, right brachial artery; $R V A$, right vertebral artery; $L V A$, left vertebral artery; $L S A$, left subclavian artery; DA, descending thoracic aorta; IMA, internal mammary artery.

$\mathrm{mmHg}$ was measured in the ascending aorta and a mean pressure of $70 \mathrm{mmHg}$ in the descending aorta. Both femoral pulses and the left radial pulse were palpable and of good volume. Twenty-four hours after operation simultaneous pressure measurements were made in the right brachial artery and right femoral artery. Systolic pressure in the right brachial artery was $120 \mathrm{mmHg}$ and in the femoral artery 108 $\mathrm{mmHg}$.

On discharge the right arm blood pressure was $130 / 90 \mathrm{mmHg}$. Nine months after operation the patient was well but has subsequently left the country and has not been restudied radiologically.

\section{Discussion}

Atresia of the aortic arch is a rare malformation and has been reported mainly in association with other cardiac anomalies such as persistent ductus arteriosus and ventricular septal defect. The anomaly is different anatomically from interruption of the aortic arch, 


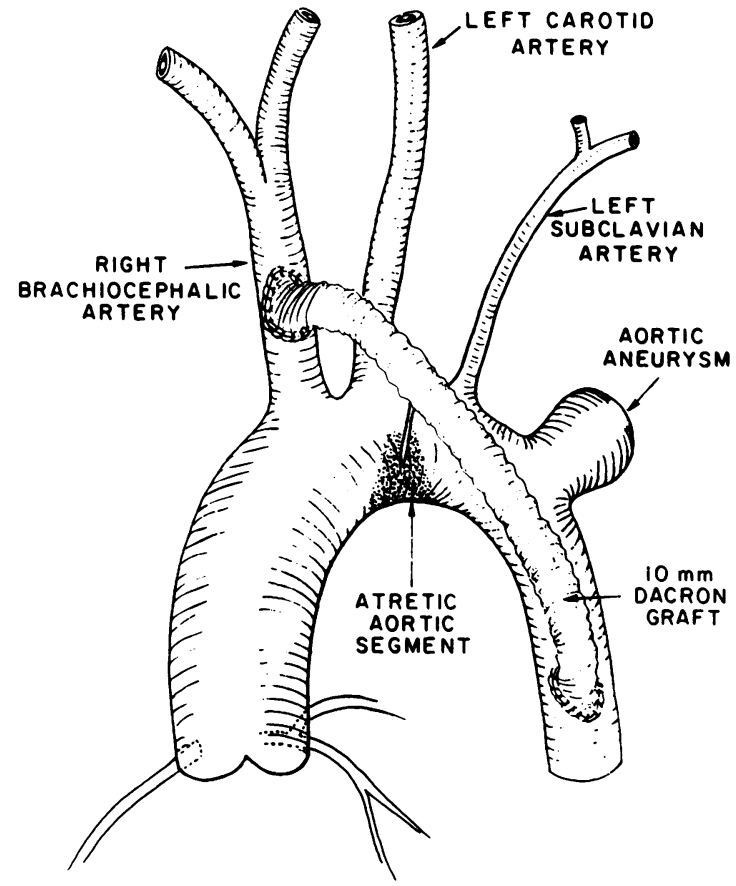

Fig. 3 Pathological anatomical findings in our patient as seen during operation and the operative treatment. The atretic segment was found between the left common carotid artery and the small left subclavian artery.

although haemodynamically similar. Whereas in interruption of the aortic arch part of the arch is absent completely, with varying distance between the two ends of the aorta, in atresia of the aortic arch the segment is short, externally narrow, and the lumen not patent. Only one previous case of aortic atresia $C$ without additional cardiac anomalies has been $\overrightarrow{\vec{s}}$ reported $^{6}$ while others were aortic arch interrup- $\frac{0}{0}$ tions ${ }^{1-578}$ (Table).

Interruption of the aortic arch was first described in $\frac{\bar{\sigma}}{\overline{0}}$ the eighteenth century by Steidele. ${ }^{10}$ The currently $\vec{\sigma}$ adopted classification ${ }^{11}$ divides the lesion into three $\varrho$ types according to the site of interruption: A, inter- $\infty$ ruption distal to the left subclavian artery; $B$, inter- $\vec{O}$ ruption between the left carotid and left subclavian arteries; C, interruption proximal to the origin of the $\vec{\omega}$ left carotid artery.

The classification has also been used in atresia of the arch. ${ }^{12}$

In a series of 184 cases of aortic interruption, ${ }^{13} 42 \%$ of the known and classifiable cases (70 of 165) were of type A, $53 \%$ of type B, and $4 \%$ type C. Almost allo cases had associated anomalies: persistent ductus, $\stackrel{\longrightarrow}{\longrightarrow}$ ventricular septal defects, aorticopulmonary window, $\bar{z}$ bicuspid aortic valve, and muscular subaortic stenosis. When associated with other cardiac malfor- $\frac{\rho}{\mathcal{S}}$ mation, the anomaly carries a $76 \%$ mortality within $\overrightarrow{0}$ the first month of life, ${ }^{14}$ the usual cause of death being $\underset{N}{\infty}$ early congestive heart failure and/or pulmonary complications. Interruption of the aortic arch with no other cardiac anomalies was thought to be incompatible with life ${ }^{14}$ until Pillsbury and associates ${ }^{2}$ 을 reported, in 1964, a case in a 16-year-old girl who was $\frac{0}{\mathbb{D}}$ operated on successfully. Our case is, to our know- $\varrho$ ledge, the oldest patient diagnosed and operated on, $\overrightarrow{\vec{O}}$ and is a case of isolated atresia of aortic arch, type B.

It is interesting that all but two reported patients with isolated aortic arch atresia carried their pathology far into adult life, in contrast to the large group of $\vec{\nabla}$ patients with additional intracardiac anomalies who

Table Clinical data of 11 cases of isolated interruption and atresia of aortic arch

\begin{tabular}{|c|c|c|c|c|c|c|c|}
\hline \multirow[t]{2}{*}{ Author } & \multirow{2}{*}{$\begin{array}{l}\text { Age } \\
\text { (yr) and } \\
\text { sex }\end{array}$} & \multirow[t]{2}{*}{ Type } & \multicolumn{2}{|c|}{$\begin{array}{l}\text { Blood pressure } \\
\text { arms (mmHg) }\end{array}$} & \multirow[t]{2}{*}{$\begin{array}{l}\text { Rib } \\
\text { notching }\end{array}$} & \multirow[t]{2}{*}{$\begin{array}{l}\text { Surgical } \\
\text { approach }\end{array}$} & \multirow[t]{2}{*}{ Operation } \\
\hline & & & Right & Left & & & \\
\hline $\begin{array}{l}\text { Evans' } \\
\text { Pillsbury et al. }{ }^{2}\end{array}$ & $\begin{array}{l}32 \mathrm{M} \\
16 \mathrm{~F}\end{array}$ & $\begin{array}{l}\text { A (interrupted) } \\
\mathrm{C} \text { (interrupted) }\end{array}$ & $\overline{140 / 100}$ & - & Right side & $\begin{array}{l}\text { No surgery } \\
\text { Left thoracotomy }\end{array}$ & $\begin{array}{l}\text { Bypass graft } \bar{c} 10 \mathrm{~mm} \\
\text { Dacron tube }\end{array}$ \\
\hline Asano et al. ${ }^{3}$ & $12 \mathrm{~F}$ & B (interrupted) & $210 / 70$ & $120 / 60$ & Right 9th rib & $\begin{array}{l}\text { Left lateral thoracotomy, } \\
\text { median sternotomy }\end{array}$ & $\begin{array}{l}\text { Bypass graft c } 12 \mathrm{~mm} \\
\text { Dacron tube }\end{array}$ \\
\hline Zetterqvist $^{4}$ & $8 M$ & B (interrupted) & - & - & No notching & Unknown & $\begin{array}{l}\text { Direct anastomosis } \\
\text { between ascending } \\
\text { and descending aorta }\end{array}$ \\
\hline Morgan et al. ${ }^{5}$ & $19 M$ & B (interrupted) & $95 / 70$ & $95 / 70$ & No notching & Left thoracotomy & $\begin{array}{l}\text { Bypass graft } \bar{c} 10 \mathrm{~mm} \\
\text { Dacron tube }\end{array}$ \\
\hline $\begin{array}{l}\text { Le Page et al. }{ }^{6} \\
\text { Kauff et al. }{ }^{7} \text { Case } 1\end{array}$ & $\begin{array}{l}56 M \\
36 M\end{array}$ & $\begin{array}{l}\text { A (atresia) } \\
\text { B (interrupted) }\end{array}$ & $\begin{array}{l}184 / 100 \\
180 / 120\end{array}$ & $\begin{array}{l}174 / 90 \\
140 / 110\end{array}$ & $\begin{array}{l}\text { Right side } \\
\text { Bilateral } \\
\text { notching }\end{array}$ & $\begin{array}{l}\text { Unknown } \\
\text { Left thoracotomy }\end{array}$ & $\begin{array}{l}\text { Direct anastomosis } \\
\text { Direct anastomosis }\end{array}$ \\
\hline Kauff et al. ${ }^{7}$ Case 2 & $49 M$ & A (interrupted) & $120 / 90$ & $210 / 95$ & $\begin{array}{l}\text { Bilateral } \\
\text { notching }\end{array}$ & Left thoracotomy & $\begin{array}{l}\text { Bypass } \\
\text { graft }\end{array}$ \\
\hline Judez et al. ${ }^{8}$ & $18 \mathrm{~F}$ & B (interrupted) & $\overline{220 / 00}$ & - & No notching & $\begin{array}{l}\text { No surgery } \\
\text { Median sternotomy and }\end{array}$ & Bypass graft c $20 \mathrm{~mm}$ \\
\hline Sharratt et al. ${ }^{9}$ & $15 \mathrm{M}$ & B (interrupted) & $220 / 90$ & - & Right side & & Dacron tube \\
\hline Present case & $65 M$ & B (atresia) & $145 / 120$ & - & Right side & Left thoracotomy & $\begin{array}{l}\text { Bypass graft c } 10 \mathrm{~mm} \\
\text { Dacron tube }\end{array}$ \\
\hline
\end{tabular}


succumbed early in childhood. ${ }^{14}$ Symptoms resembled those of long-standing systemic hypertension or aortic coarctation: headaches, fainting spells, visual disturbances, dysphasia, memory loss, dyspnoea, and leg pains on walking. Central nervous system symptoms seen in cases with interruption of types B and C are probably the result of vertebral steal. ${ }^{49}$ Retrograde flow from the left vertebral and carotid arteries to the descending aorta was present in our patient and carotid arteriograms showed filling of the vertebrobasilar system from an injection into the right carotid artery (Fig. 2A and B). Reconstitution of blood flow to the descending aorta was achieved at operation, either by direct anastomosis (cases $4,7,9$ ) or by use of a synthetic tube graft, depending on the anatomical distance between the two end pouches of the ascending and descending aorta and the feasibility of bringing them together. Operation was successful in all patients included in this review. Surgical treatment of the anomaly is relatively simple and produces distinct improvement in both neurological and cardiovascular status.

\section{References}

1 Evans W. Congenital stenosis (coarctation), atresia, and interruption of the aortic arch - (a study of twenty-eight cases). Qf Med (NS) 1933; 2: 1-31.

2 Pillsbury RC, Lower RR, Shumway NE. Atresia of the aortic arch. Circulation 1964; 30: 749-54.

3 Asano K, Shiozaki K, Eguchi S, Irisawa T. Congenital aortic arch interruption: report of a case, surgically treated with success. Fpn Heart f 1967; 8: 196-201.

4 Zetterqvist P. Atypical coarctation of the aorta with bilateral vertebral-subclavian pathway. Scand $\mathcal{f}$ Thorac Cardiovasc Surg 1967; 1: 68-75.

5 Morgan JR, Forker AD, Fosburg RG, Neugebauer MK, Rogers AK, Bemiller CR. Interruption of the aortic arch without a patent ductus arteriosus. Circulation 1970; 42: 961-5.

6 Le Page JR, Viamonte M Jr, Jude JR. Complete interruption of the arch of the aorta: an enigma? $\mathcal{F}$ Can Assoc Radiol 1971; 22: 60-4.

7 Kauff MD, Bloch J, Baltaxe HA. Complete interruption of the aortic arch in adults. Radiology 1973; 106: 53-7.

8 Judez VM, Maitre MJ, de Artaza M, deMiguel JMF, Valles F, Marquez J. Interruption of aortic arch without associated cardiac abnormalities. Br Heart $\mathcal{F}$ 1974; 36: 313-7.

9 Sharratt GP, Carson P, Sanderson JM. Complete interruption of aortic arch, without persistent ductus arteriosus, in an adult. $\mathrm{Br}$ Heart $\mathcal{F}$ 1975; 37: 221-4.

10 Steidele RJ. Sammlung verschiedener in der chirurgischpraktischer Lehrschule gemachten Beobachtungen. vol. 2. Vienna: Gräffer, 1777-1778: 114.

11 Celoria GC, Patton RB Congenital absence of the aortic arch. Am Heart f 1959; 58: 406-13.

12 Tawes RL Jr, Panagopoulos P, Aberdeen E, Waterston DJ, Bonham-Carter RE. Aortic arch atresia and interruption of the aortic arch. Experience in 11 cases of operation. I Thorac Cardiovasc Surg 1969; 58: 492-501.

13 Van Praagh R, Bernhard WF, Rosenthal A, Parisi LF, Fyler DC. Interrupted aortic arch: surgical treatment. Am $\mathcal{F}$ Cardiol 1971; 27: 200-11.

14 Roberts WC, Morrow AG, Braunwald E. Complete interruption of the aortic arch. Circulation 1962; 26: 3759.

Requests for reprints to Dr Simcha Milo, Department of Thoracic and Cardiovascular Surgery, The Chaim Sheba Medical Center, Tel-Hashomer, Israel. 